\title{
Posterior open-door laminoplasty secured with titanium miniplates vs anchors: a comparative study of clinical efficacy and cervical sagittal balance
}

\author{
Dongyue Li, Yong Hai ${ }^{*}$, Xianglong Meng, Jincai Yang and Peng Yin
}

\begin{abstract}
Objective: Posterior open-door laminoplasty (PODL) is a common procedure for treating multilevel cervical spondylotic myelopathy (MCSM). Little information is available regarding the cervical sagittal balance and surgical efficacy of PODL when securing with different methods. Therefore, this study aims to investigate the clinical outcomes and the changes in cervical sagittal parameters and balance associated with PODL secured with titanium miniplates vs anchors.
\end{abstract}

Method: A retrospective analysis was performed on the clinical data of 79 patients with MCSM who were treated in our institution from January 2015 to December 2016. Among them, 42 patients were treated by PODL secured with titanium miniplates (group A) and 37 patients by PODL secured with anchors (group B). Surgical time, intraoperative blood loss, hospital stay, hospitalized cost, VAS scores of neck pain, JOA scores, neck disability index (NDI), and improvement rate of spinal neurological function (IRNF) were recorded before surgery and at 12 months after surgery. Before surgery, at 1 month and 2 years after surgery, the following radiological parameters were recorded and compared on the lateral cervical X-ray images: the distance from the vertical axis of C2 sagittal plane to the posterior superior edge of C7 (C2-7 SVA), the inclusion angle of tangent between C2 and C7 trailing edge (C2-7 Cobb angle), and the intersection angle between the upper edge of T1 and the horizontal line (T1 Slope).

Result: Comparing the two groups, there were no significant differences in surgical time, intraoperative blood loss, hospital stay, VAS, JOA, and NDI scores before surgery $(P>0.05)$; however, the hospitalized cost of group A were much higher than those of the group $B(P<0.05)$. At 2 years after surgery in the two groups, there was a significant reduction in VAS and NDI scores $(P<0.05)$, and JOA scores increased significantly $(P<0.05)$. In addition, there were no significant differences in VAS, JOA and IRNF between the two groups $(P>0.05)$; however, NDI scores of group A were better than those of group $B(P<0.05)$. In radiological parameters, before surgery, the two groups showed no significant differences in C2-7 SVA, C2-7 Cobb angle, and T1 slope $(P>0.05)$; however, after surgery, C2-7 SVA and T1 slope increased $(P<0.05)$, while $C 2-7$ Cobb angle decreased $(P<0.05)$. At 2 years after surgery, the two groups did not differ significantly in C2-7 Cobb angle and T1 slope $(P>0.05)$, while C2-7 SVA of group A was superior to that of group $B(P<0.05)$. The difference value of C2-7 SVA measured before and after surgery was correlated negatively with that of NDI scores $(P<0.05)$.

(Continued on next page)

\footnotetext{
* Correspondence: prof_haiyong@126.com

Orthopaedic Department, Chaoyang Hospital Affiliated to Capital Medical University, Beijing 100020, China
}

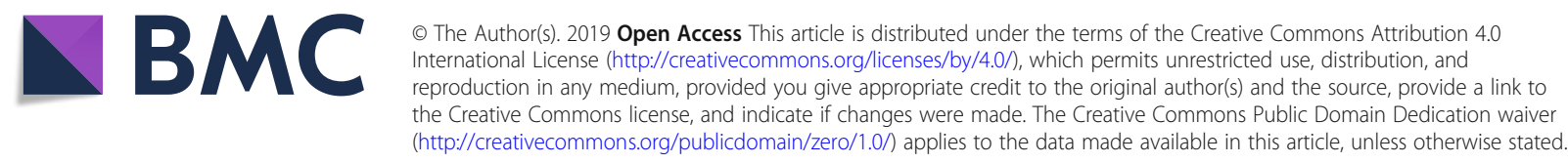




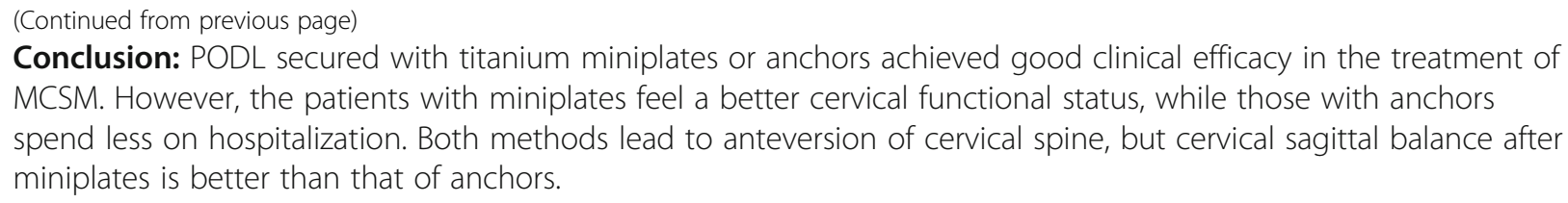

Keywords: Posterior open-door laminoplasty, Titanium miniplates, Anchors, Clinical efficacy, Cervical sagittal balance

\section{Introduction}

Cervical degenerative disease is a major cause of spinal diseases, and its incidence has been rising in the elderly people [1-3]. Posterior open-door laminoplasty (PODL) is the primary treatment for multi-segmental cervical spondylotic myelopathy (MCSM), developmental cervical spinal canal stenosis, ossification of cervical posterior longitudinal ligament, and so on. Studies have shown this surgical approach has definite and enduring efficacy in releasing spinal compression and improving the function of nervous system [17]. After PODL, it is usually necessary to firmly fix the opened laminae in order to maintain the enlargement and decompression of the spinal canal. To do so, the commonly used methods include silk suspension, suture anchor, and titanium miniplate (centerpiece), which can pry open the lamina on the open-door side [1, 2, 5-10].

Silk suspension is to tie the silk into the space between the spinous process and articular capsule of the doorshaft side. But this method has lower biomechanical strength, and re-closure of the opened lamina may occur, resulting in relapse of the neurological symptoms $[1,8]$. It has been reported that PODL secured with either miniplates or anchors can achieve a good clinical effect $[1,2,8,10]$, but few reports are concerned with the comparison of the two approaches. Whatever the approach, damage to muscle group and ligaments of the neck seems inevitable, which may further disrupt cervical sagittal balance, leading to straightening of normal cervical lordosis or even kyphosis [11-13]. More studies are devoted to coronal-sagittal balance of the lumbar spine and the influence of spinal-pelvic parameters on postoperative lumbar spine [14, 15], while few are focused on the postoperative cervical sagittal parameters and changes in cervical sagittal balance.

In this study, clinical efficacy and radiologic parameters were compared between PODL secured with titanium miniplates and anchors. The influence of different surgical approaches on cervical sagittal balance was discussed, and the potential correlation between cervical sagittal parameters and clinical efficacy was analyzed.

\section{Methods}

\section{Clinical data}

From January 2015 to December 2017, 79 patients with MCSM were recruited in our institution. They were selected according to the following criteria. Inclusion criteria include the following: Sensory and motor disorders of the four limbs or sphincter of Oddi dysfunction, confirmed as MCSM by cervical X-ray, CT, MRI and neurological examination; compressed cervical segments $\geq 3$ by preoperative MRI; these patients received PODL in the C3-7 vertebrae; they were followed up for at least 2 years after surgery, and all of them had radiologic data; all of them received bone density examination before surgery, and none of them had severe osteoporosis, with $\mathrm{T}$ value $>-2.5$. Exclusion criteria were as follows: Nondegenerative cervical diseases such as trauma, deformity, tuberculosis, tumor, and so on.

Before surgery, all patients were informed of the advantages and disadvantages of the two surgical approaches without any bias, and they were allowed to make their own choice. Depending on the surgical approach, the patients were divided into two groups: (1) PODL secured with titanium miniplates (centerpiece) (group A) and (2) PODL secured with anchors (group B). All surgeries were performed by the same group of surgeons.

\section{Surgical procedures}

After general anesthesia, a Mayfield head clamp was used to immobilize the head and neck in a flexed position under the prone position, with the trunk slightly elevated. A posterior midline approach was adopted. The skin, subcutaneous tissues, and nuchal ligament were cut open layer by layer. The laminae from $\mathrm{C} 3$ to $\mathrm{C} 7$ were exposed by stripping the paravertebral muscle from the spinous process and laminae to the medial margin of bilateral facet joints. The more severely affected side was taken as the open side, and the contralateral side as the door-shaft side. If the symptoms were of comparable severity, then the left side was taken as the open-door side, and the right side as the door-draft side. A groove was made at the boundary between bilateral facet joints and laminae. The entire layer of lamina was severed on the open-door side, and the inner layer of cortex was preserved on the door-shaft side. The ligamentum flavum were severed at $\mathrm{C} 2-3$ and $\mathrm{C} 7-\mathrm{T} 1$ on the open-door side, and the laminae of each segment were opened successively. 
Group A (Titanium miniplates): Centerpiece miniplates of appropriate length was installed between the lateral mass and opened lamina; the opened lamina was held with the claw-shaped clamp and immobilized with one to two titanium pins; another two titanium pins were used to immobilize the lateral mass on the opendoor side.

Group B (Anchors): Five silk anchors were inserted into the lateral mass on the door-shaft side. A hole was drilled on the opened spinous process, with the silk passing through the hole to immobilize the opened laminae. Strict hemostatic measures were adopted, and the incision was washed with normal saline. A drainage tube was dwelled outside of the spinal dura mater, and the incision was sutured layer by layer.

Antibiotics were given prophylactically for up to $48 \mathrm{~h}$ after surgery. Considering larger surgical incisions and more drainage volume, the drain was kept for more than $48 \mathrm{~h}$ in all patients. When the drainage volume was less than $50 \mathrm{ml} / 24 \mathrm{~h}$, the drain would be removed. The patients were assisted in off-bed movement wearing cervical collar. They began to take exercises of posterior cervical muscles after 3 or 4 weeks.

\section{Efficacy evaluation and radiographic assessment}

Surgical time, intraoperative blood loss, hospital stay, hospitalized cost, and Visual analogue score (VAS) of neck pain were recorded in the two groups. Before surgery and at 2 years after surgery, JOA [16] (Japanese Orthopaedic Association) scale ranging from 0 to 17 points was used to assess the spinal functions. Improvement rate of spinal neurological function (IRNF) was calculated as follows: [(Postoperative JOA score - preoperative JOA score $) /(17$ - preoperative JOA score $) \times$ $100 \%]$. IRNF was assessed postoperatively for nerve function on this basis. Neck disability index (NDI) [17] was used to assess the cervical functional status. NDI ranged from 0 to 50 , and the lower the score, the lower the severity of cervical dysfunction.

All patients received standard lateral cervical X-ray before surgery and at 1 month and 2 years after surgery. It was required that the superior margin of $\mathrm{T} 1$ vertebra was exposed. The radiologic parameters were measured by one orthopedist and one radiologist. The means were taken of all measurements. Parameters of cervical sagittal balance measured and recorded from the standard lateral cervical X-ray images at the above-mentioned three time points included the following: the distance between the vertical axis of $\mathrm{C} 2$ sagittal plane and the posterior superior edge of C7 (C2-7 sagittal vertical axis; SVA), the inclusion angle of tangent between $\mathrm{C} 2$ and $\mathrm{C} 7$ trailing edge (C2-7 Cobb angle), and the intersection angle between the upper edge of $\mathrm{T} 1$ and the horizontal line (T1 slope) (Fig. 1).

\section{Statistics analyses}

Statistical analyses were performed using SPSS 17.0 software. Measurements were expressed as $(\bar{x} \pm$ SD). Pairedsamples $t$ test was performed for intragroup comparison, and independent $t$ test for intergroup comparison. Several measurements of the same radiologic parameters were compared by using repeated measures analysis of variance (ANOVA). The relationship between radiologic parameters and clinical indicators was tested by Pearson's correlation analysis. $P<0.05$ indicated significant difference.

\section{Results}

\section{Surgical results}

Group A included 42 patients, including 27 males and 15 females with an average age of $61.2 \pm 8.8$ years old (47-77 years old) and average course of $45.3 \pm 7.7$ months; group B included 37 patients, including 23 males and 14 females with an average age of $60.9 \pm 8.3$ years old (45-76 years old) and average course of $43.7 \pm$ 9.4 months. All patients were followed up for at least 2 years. The average time of drain removal was $3.10 \pm$ 0.94 days. In group $\mathrm{A}$, one patient developed epidural hematoma after operation, and the clinical symptoms of the patient improved significantly after timely removal of the hematoma. Group B had one case of wound infection. After debridement and anti-infection treatment, the wound healed well. Other patients did not have such complications as neurovascular injury, cerebrospinal fluid leakage, loosening of internal fixation, and so on.

\section{Clinical results}

Comparing the two groups, there were no significant differences in surgical time, intraoperative blood loss, hospital stay, VAS, JOA, and NDI scores before surgery $(P>$ $0.05)$; however, the hospitalized cost of group A were much higher than those of the group B $(P<0.05)$. At 2 years after surgery, there was a significant reduction in VAS scores of neck pain (group A $t=8.573$, group B $t=$ 4.743, $P<0.05$ ); JOA scores increased significantly (group A $t=15.490$, group B $t=24.652, P<0.05$ ); NDI scores decreased significantly (group A $t=26.119$, group B $t=17.683, P<0.05)$. At 2 years after surgery, neither were there significant differences in JOA scores and IRNF between the two groups $(P>0.05)$; however, NDI scores of group A were better than that of group B $(P<$ 0.05) (Table 1).

\section{Radiographic results Cervical sagittal parameters on X-ray}

Measurements of radiologic parameters in the two groups are shown in Table 2. Within each group, after surgery, both C2-7 SVA and T1 slope increased significantly $(P<0.05)$, while the $\mathrm{C} 2-7$ Cobb angle decreased 

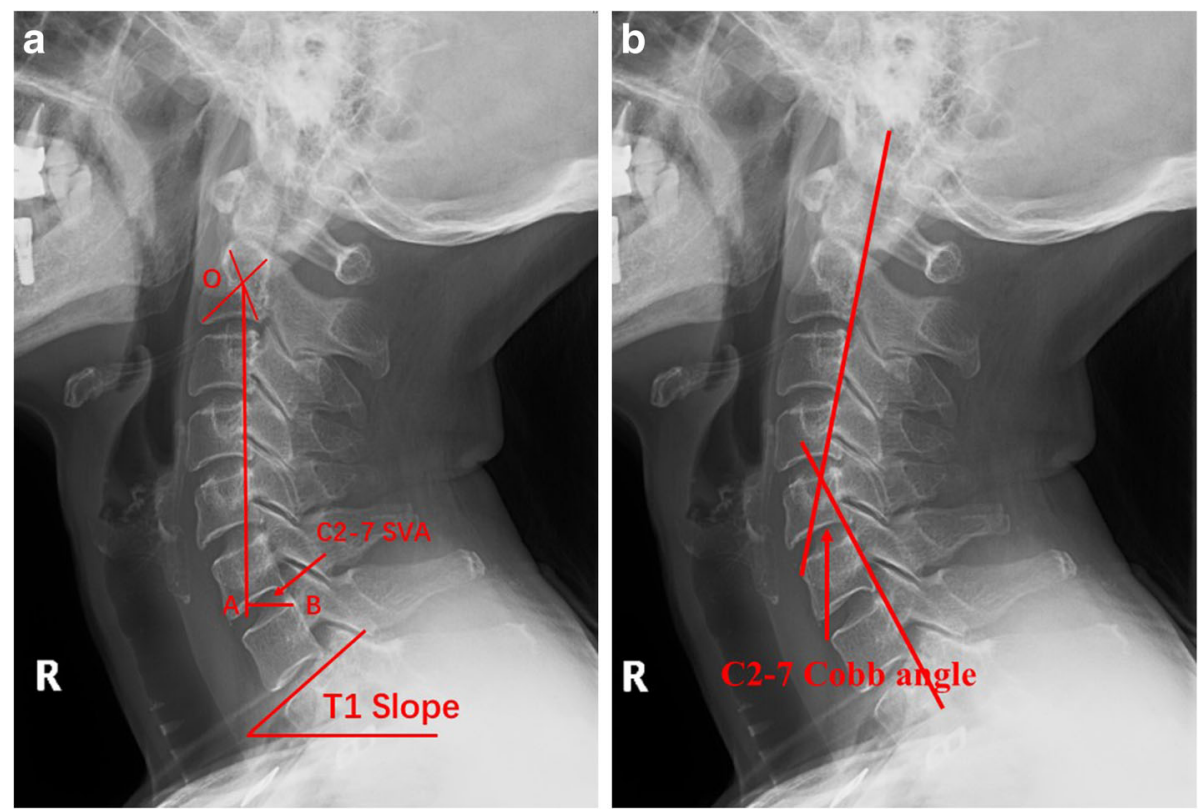

Fig. 1 Measurement of cervical sagittal imaging parameters. a C2-7 SVA is the distance between the vertical axis of C2 sagittal plane (OA) and the posterior superior edge of C7 (point B), that is, the length of AB. T1 slope is the intersection angle between the upper edge of T1 and the horizontal line. $\mathbf{b}$ C2-7 Cobb angle is the inclusion angle of tangent between C2 and C7 trailing edge

$(P<0.05)$. There were significant changes in C2-7 SVA, C2-7 Cobb angle, and T1 slope on sagittal parameters at 1 month and 2 years after surgery in each group (group A $t=4.051, t=13.180, t=7.795, P<0.05$; group $\mathrm{B} t=$ 14.205, $t=15.848, t=3.321, P<0.05)$.

The sagittal parameters of C2-7 SVA, C2-7 Cobb angle, and $\mathrm{T} 1$ slope were not significant differences $(P>$
$0.05)$ between the two groups before surgery and at 1 month after surgery. At 2 years after surgery, no significant differences were found in $\mathrm{C} 2-7 \mathrm{Cobb}$ angle and $\mathrm{T} 1$ slope $(P>0.05)$; however, there were significant differences in C2-7 SVA $(P<0.05)$, and group A was superior to that of group B. (Table 2). For description of representative cases, see Fig. 2.

Table 1 Baseline information, VAS, JOA, and NDI scores in the two groups ( $\bar{x} \pm \mathrm{SD})$

\begin{tabular}{|c|c|c|c|c|}
\hline Item & Group A $(n=42)$ & Group B $(n=37)$ & $t$ value & $P$ value \\
\hline Age (years) & $61.2 \pm 8.8$ & $60.9 \pm 8.3$ & 0.110 & 0.913 \\
\hline Course of disease (months) & $45.3 \pm 7.7$ & $43.7 \pm 9.4$ & 0.580 & 0.565 \\
\hline Surgical time (min) & $116.1 \pm 16.7$ & $113.9 \pm 15.1$ & 0.782 & 0.439 \\
\hline Intraoperative blood loss (ml) & $184.4 \pm 35.8$ & $170.4 \pm 34.3$ & 1.272 & 0.211 \\
\hline Hospital stay (days) & 7.6 & 7.5 & 0.525 & 0.603 \\
\hline Hospitalized cost (Yuan) & 104112.3 & 67331.5 & 18.768 & 0.000 \\
\hline \multicolumn{5}{|l|}{ VAS scores of neck pain } \\
\hline Before surgery & $2.7 \pm 0.92$ & $2.5 \pm 1.04$ & 0.961 & 0.342 \\
\hline At 2 years after surgery & $1.3 \pm 0.65$ & $1.4 \pm 0.50$ & 0.541 & 0.592 \\
\hline \multicolumn{5}{|l|}{ JOA scores } \\
\hline Before surgery & $8.8 \pm 1.09$ & $8.4 \pm 0.97$ & 1.304 & 0.200 \\
\hline At 2 years after surgery & $13.5 \pm 1.29$ & $12.9 \pm 1.37$ & 1.247 & 0.230 \\
\hline IRNF & $56.9 \pm 13.5$ & $49.6 \pm 12.9$ & 1.790 & 0.081 \\
\hline \multicolumn{5}{|l|}{ NDI scores } \\
\hline Before surgery & $42.7 \pm 3.04$ & $42.3 \pm 2.76$ & 0.280 & 0.718 \\
\hline At 2 years after surgery & $22.2 \pm 2.44$ & $24.4 \pm 3.62$ & 2.501 & 0.017 \\
\hline
\end{tabular}


Table 2 Cervical sagittal parameters on X-ray in the two groups $(\bar{x} \pm$ SD)

\begin{tabular}{|c|c|c|c|c|}
\hline Item & Group A $(n=42)$ & Group B $(n=37)$ & $t$ value & $P$ value \\
\hline \multicolumn{5}{|l|}{ C2-7 SVA (mm) } \\
\hline Before surgery & $20.3 \pm 6.9$ & $20.1 \pm 5.4$ & 0.856 & 0.394 \\
\hline At 1 month after surgery & $34.8 \pm 5.7$ & $33.9 \pm 5.1$ & 1.767 & 0.085 \\
\hline At 2 years after surgery & $22.4 \pm 4.1$ & $24.9 \pm 4.7$ & 3.113 & 0.002 \\
\hline F value * & 6.978 & 161.014 & & \\
\hline$P$ value* & 0.006 & 0.000 & & \\
\hline \multicolumn{5}{|l|}{ C2-7 Cobb angle $\left(^{\circ}\right)$} \\
\hline Before surgery & $21.4 \pm 6.6$ & $21.1 \pm 5.8$ & 0.834 & 0.406 \\
\hline At 1 month after surgery & $14.8 \pm 3.8$ & $14.2 \pm 3.3$ & 0.799 & 0.426 \\
\hline At 2 years after surgery & $19.5 \pm 6.3$ & $18.5 \pm 5.1$ & 1.693 & 0.093 \\
\hline F value $^{*}$ & 124.228 & 49.836 & & \\
\hline$P$ value* & 0.000 & 0.001 & & \\
\hline \multicolumn{5}{|l|}{ T1 Slope $\left(^{\circ}\right)$} \\
\hline Before surgery & $24.7 \pm 2.4$ & $24.4 \pm 3.8$ & 1.025 & 0.307 \\
\hline At 1 month after surgery & $33.2 \pm 3.5$ & $32.9 \pm 3.2$ & 1.166 & 0.246 \\
\hline At 2 years after surgery & $26.5 \pm 2.7$ & $28.1 \pm 3.1$ & 1.814 & 0.072 \\
\hline F value $^{*}$ & 26.133 & 33.135 & & \\
\hline$P$ value* & 0.001 & 0.000 & & \\
\hline
\end{tabular}

Note: *indicates statistics of intragroup comparison by using repeated measures ANOVA

\section{Relationship between radiologic parameters and clinical indicators}

According to statistical analyses, when comparing the two groups at 2 years after surgery, there were significant differences in NDI scores and C2-7 SVA $(P<0.05)$. To facilitate statistical comparison, the difference value in NDI scores and C2-7 SVA at 2 years after surgery between the two groups were calculated (Table 3). Pearson correlation coefficients were calculated. The difference value in NDI scores was correlated negatively with that in C2-7 SVA $(r=-0.433, P<0.05)$.

\section{Discussion}

MCSM can cause severe damage to the spinal function. Given to the grim consequences of progression, early surgery is important after confirmed diagnosis, so as to release spinal compression [1-8]. When three or more segments are involved, posterior cervical approach is preferred to ensure the clinical outcomes and safety [1, $2,6]$. PODL is one of the common treatments for MCSM, which can increase vertebral canal volume and release compression of spinal cord and nerve roots, and the aim is to create enough room for the recovery of the nerves and spinal cord [1, 2, 6, 7].

In our study, PODL was performed using either titanium miniplates or anchors. Silk is fixed in screw, and they are made into a unity of anchor. The unity can prevent slip and rupture of the silk at the root of the screw in the lateral mass; moreover, the anchor has locking function and can prevent screw dislocation, which may otherwise lead to reclosure. This method proves to have a reliable open-door effect. Titanium miniplate $[1,2,7$, 8 ] is to install the centerpiece miniplate between the lamina and lateral mass on the open-door side, so as to enlarge the vertebral canal and to release spinal compression. The rigid support provided by the centerpiece miniplate can effectively prevent postoperative reclosure or loss of door-closing amplitude, so as to ensure the clinical efficacy. In our study, group A received immobilization with titanium miniplates, and group B immobilization with silk anchors. At 2 years after surgery, VAS, JOA, and NDI scores were all improved significantly than before $(P<0.05)$. This indicated that either approach could achieve a satisfactory clinical effect. It was found that at 2 years after surgery, NDI scores of group A were much better than those of group $B(P<0.05)$. NDI is a subjective evaluation of patients' cervical functional status. Several items of NDI deal with the subjective perception of comfort. Though bias seems inevitable with NDI, postoperative cervical functional status of the patient does have a considerable impact on the patients' life quality [18]. We think that NDI has a certain clinical significance and serves as an important measure for surgical outcomes. Although PODL-secured titanium miniplates incurred greater hospitalized cost than using anchors $(P<0.05)$, the former provided higher cervical comfort for the patient after surgery. 

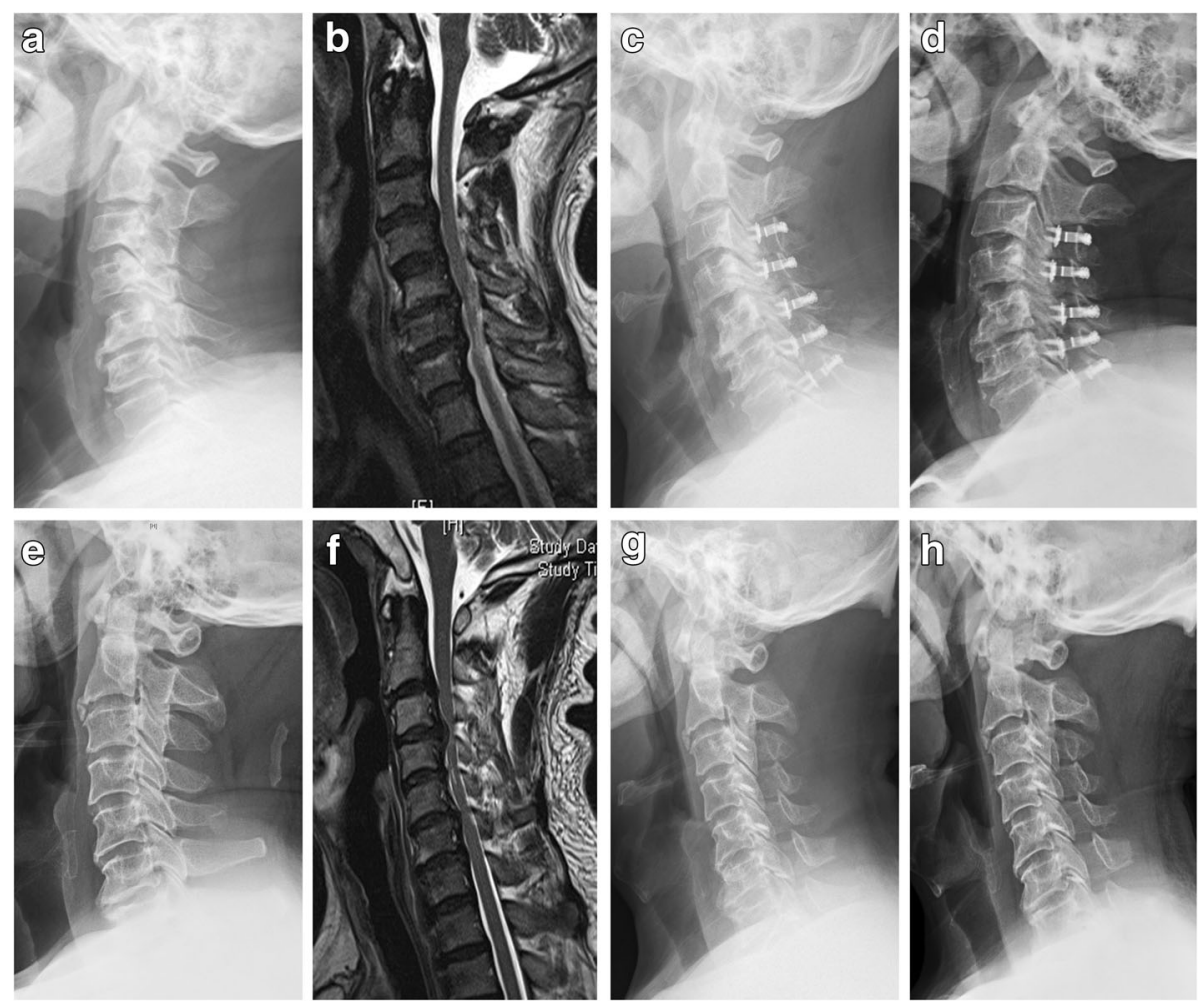

Fig. 2 Comparison of cervical sagittal imaging parameters between two surgical approaches. a-d PODL secured with titanium miniplates (centerpiece). a Preoperative lateral cervical X-ray showed cervical degenerative and multi-segment spinal stenosis, with C2-7 SVA of 10.6 mm. b Preoperative cervical MRI showed multi-segment spinal compression at C3-7 segments. c At 1 month after surgery, lateral cervical X-ray showed that there was apparent increase of cervical canal width, with significant cervical anteversion and C2-7 SVA of $29.6 \mathrm{~mm}$. $\mathbf{d}$ At 2 years after surgery, lateral cervical X-ray indicated good position of the titanium miniplates, and there was significant improvement of cervical anteversion, with the C2-7 SVA of $12.1 \mathrm{~mm}$. e-h PODL secured with silk anchors. e Preoperative lateral cervical X-ray showed cervical degenerative and multi-segment spinal stenosis, with C2-7 SVA of $20.5 \mathrm{~mm}$. f Preoperative cervical MRI showed multi-segment spinal compression at C3-7 segments. g At 1 month after surgery, lateral cervical X-ray showed that there was apparent increase of cervical canal width, with significant cervical anteversion and C2-7 SVA of $33.6 \mathrm{~mm}$. $\mathbf{h}$ At 2 years after surgery, lateral cervical X-ray indicated good position of the anchors, and there was mild improvement of anteversion, with the C2-7 SVA of $29.1 \mathrm{~mm}$

Cervical sagittal balance is an important component of balance of the entire spine. Changes in cervical sagittal parameters after PODL will affect sagittal balance of the cervical spine or even the entire spine [11-13]. C2-7 SVA, C2-7 Cobb angle, and T1 slope are important measures of cervical sagittal balance [11-13, 19]. After surgery, both C2-7 SVA and T1 slope increased in the two groups than before $(P<0.05)$, while $\mathrm{C} 2-7 \mathrm{Cobb}$ angle decreased $(P<0.05)$. The result indicated conspicuous postoperative cervical anteversion. One major cause might be the damage to posterior cervical muscleligament complex when exposing the bilateral lamina.
Additional cause might be that during door-opening operations in $\mathrm{C} 3$ and $\mathrm{C}$, attachments of the muscle in the spinous processes of $\mathrm{C} 3$ and $\mathrm{C} 7$ might be damaged with severing of laminae from the lateral mass on the opendoor side. The above factors may lead to damage of muscle group and bony structure, which further affects cervical instability. As a result, anteversion may occur due to failure to maintain normal cervical curvature. Cervical anteversion is most significant at an early stage after surgery. Along with the progression of time, many patients may still fail to recover to preoperative curvature. Disruption of cervical sagittal balance as measured

Table 3 Correlation analysis between radiologic parameters and clinical indicators $(\bar{x} \pm$ SD)

\begin{tabular}{|c|c|c|c|c|}
\hline \multirow[t]{2}{*}{ Item } & \multirow[t]{2}{*}{ Group A } & \multirow[t]{2}{*}{ Group B } & \multicolumn{2}{|c|}{ Difference in NDI at 2 year after surgery } \\
\hline & & & $R$ value & $P$ value \\
\hline Difference in NDI & $21.2 \pm 2.9$ & $17.9 \pm 3.7$ & & \\
\hline Difference in C2-7 SVA (mm) & $2.21 \pm 0.71$ & $4.77 \pm 1.04$ & -0.433 & 0.005 \\
\hline
\end{tabular}


by C2-7 SVA, C2-7 Cobb angle, and T1 slope at 1 month after surgery was most apparent. These parameters were improved $(P<0.05)$ at 2 year after surgery, but cervical sagittal balance still did not recover to the preoperative curvature $(P<0.05)$.

However, controversy is still going on as to which radiologic parameter is of the highest clinical significance among all parameters of cervical sagittal balance. According to Ling et al. [19], C2-7 SVA was the most important radiologic parameter among the followings: C0-2 Cobb angle, C2-7 Cobb angle, C4-7 Cobb angle, C0-7 SVA, C1-7 SVA, C2-7 SVA, C7 Slope, T1 slope, angle of cervical endplate, McGregor's slope, elbow angle, craniospinal angle, and thoracic inlet angle. In this study, both groups had a significant increase in C2-C7 SVA after surgery $(P<0.05)$, indicating cervical anteversion. But at 2 years after surgery, group A achieved a much better recovery than group B $(P<0.05)$. Immobilization with silk anchors might cause complete damage to the bony structure on the open-door side. As a result, the cervical spine loses the support offered by bony structure on this side, leading to cervical instability to varying degrees. Moreover, posterior cervical muscle group was damaged, and the normal physiological curvature of the cervical spine could not be effectively maintained, leading to persistent anteversion [20]. However, miniplates provides a stable bridging fixation between the opened lamina and ipsilateral lateral mass, so that the opened lamina and lateral mass for the same segment can form a whole unity. In the meantime, rigid fixation can be provided for the open-door side, so that the original support by the body structure can be restored as much as possible. The opened lamina will be subjected to uniform stress under flexion and extension and rotation of the cervical spine, thereby increasing the possibility of restoring the normal cervical stress [21]. Besides, immobilization with miniplates can also provide solid stabilization to the door-shaft side, which is conducive to bony union on this side [7]. Cervical anteversion after PODL secured with miniplates might be only the result of damage to the posterior muscle group.

As to whether the radiologic parameters of cervical sagittal balance would affect clinical symptoms of the patients, Tang et al. [11] reported 113 patients receiving PODL with multilevel fusion. It was found that C2-7 SVA was correlated negatively with SF-36 and cervical anteversion would affect the surgical efficacy. Under normal physiological curvature of the cervical spine, posterior muscle group has the lowest energy consumption, and therefore, the patient has the highest degree of comfort. But if cervical anteversion occurs due to damage of bony structure and posterior muscle group after PODL, the posterior muscle group no longer has the lowest energy consumption [19]. This will further lead to such clinical symptoms as fatigue, discomfort, and pain of the posterior neck. Two different approaches were adopted in this study. The results showed that the difference value in NDI scores was correlated negatively with that in C2-7 SVA $(r=-0.433, P<0.05)$. This means disruption of cervical sagittal balance would definitely impair cervical functional status, which further lowered cervical comfort of patients.

However, the present study still had the following limitations: (1) The sample size was small. (2) The duration of follow-up was limited. Our conclusions need to be further verified through studies with larger sample size and longer follow-up.

\section{Conclusion}

Taken together, PODL secured with titanium miniplates or anchors could achieve satisfactory improvement of neurological function for MCSM. However, the use of miniplates led to better cervical functional status, while the use of anchors reduced the hospitalized cost. Significant changes occurred in cervical sagittal balance after surgery using either approach, mainly presenting as cervical anteversion, which was most serious at the early stage after surgery. But this condition would improve with time, and alteration of sagittal balance had an impact on cervical comfort. It was revealed that the recovery of cervical sagittal balance was better secured with the miniplates than anchors.

\section{Abbreviations}

ANOVA: Analysis of Variance; IRNF: Improvement rate of spinal neurological function; JOA: Japanese Orthopaedic Association; MCSM: Multi-segmental cervical spondylotic myelopathy; NDI: Neck disability index; PODL: Posterior open-door laminoplasty; SVA: Sagittal vertical axis; VAS: Visual analogue score

\section{Acknowledgements}

We would like to thank all the participants in the studies.

\section{Authors' contributions}

LDY contributed to the study design, the writing of the paper, and drafting of the manuscript. HY performed the surgeries and participated in the design of the study. MXL and YJC collected and analyzed the data. YP reviewed and edited the manuscript. All authors read and approved the final manuscript.

\section{Funding}

None.

\section{Availability of data and materials}

All data used and analyzed during this study are available from the corresponding author upon reasonable request.

\section{Ethics approval and consent to participate}

This research was approved by the ethics committee of the Chaoyang Hospital Affiliated to Capital Medical University and agreed that participation was given to participants. Because of the retrospective nature of the study, informed consent was waived.

\section{Consent for publication}

Written informed consent for publication of their clinical details and/or clinical images was obtained from the patient/parent/guardian/relative of the patient. 


\section{Competing interests}

The authors declare that they have no competing interests.

Received: 8 August 2019 Accepted: 5 November 2019

Published online: 28 November 2019

\section{References}

1. Chen H, Deng Y, Li T, et al. Clinical and radiography results of mini-plate fixation compared to suture suspensory fixation in cervical laminoplasty: a five-year follow-up study. Clin Neurol Neurosurg. 2015;138:188-95 https:// doi.org/10.1016/j.clineuro.2015.09.004

2. Yeh $K T, Y u T C$, Chen $I H$, et al. Expansive open-door laminoplasty secured with titanium miniplates is a good surgical method for multiple-level cervical stenosis. J Orthop Surg Res. 2014;9:49 https://doi.org/10.1186/ s13018-014-0049-8.

3. Nagoshi N, Tsuji O, Okada E, et al. Clinical indicators of surgical outcomes after cervical single open-door laminoplasty assessed by the Japanese Orthopaedic Association Cervical Myelopathy Evaluation Questionnaire. Spinal Cord. 2019;57(8):644-51 https://doi.org/10.1038/s41393-019-0258-4.

4. Signorelli F, Trevisi G, Bianchi F, et al. (2018) Clinical and radiological outcomes following open door laminoplasty: a single center evolution of the technique. J Neurosurg Sci [Epub ahead of print]. https://doi.org/10. 23736/S0390-5616.18.04555-1

5. Mo Z, Li D, Zhang R, et al. (2018) Comparison of three fixation modalities for unilateral open-door cervical laminoplasty: a systematic review and network meta-analysis. Neurosurg Rev [Epub ahead of print] https://doi.org/ 10.1007/s10143-018-1035-0.

6. Lin $\mathrm{X}$, Chen $\mathrm{K}$, Tang $\mathrm{H}$, et al. Comparison of anchor screw fixation versus mini-plate fixation in unilateral expansive open-door laminoplasty for the treatment of multi-level cervical spondylotic myelopathy. Medicine (Baltimore). 2018;97(49):e13534 https://doi.org/10.1097/MD. 0000000000013534.

7. Wang LN, Wang L, Song YM, et al. Clinical and radiographic outcome of unilateral open-door laminoplasty with alternative levels centerpiece miniplate fixation for cervical compressive myelopathy: a five-year follow-up study. Int Orthop. 2016;40(6):1267-74 https://doi.org/10.1007/s00264-0163194-3.

8. Heller JG, Raich AL, Dettori JR, et al. Comparative effectiveness of different types of cervical laminoplasty. Evid Based Spine Care J. 2013;4(2):105-15 https://doi.org/10.1055/s-0033-1357361.

9. Matsuoka $H$, Ohara $Y$, Tomita $Y$, et al. Initial radiological findings utilizing titanium basket for cervical open door laminoplasty. Surg Neurol Int. 2017 7(8):217 https://doi.org/10.4103/sni.sni_204_17.

10. Lee JY, Hanks SE, Oxner W, et al. Use of small suture anchors in cervical laminoplasty to maintain canal expansion: a technical note. J Spinal Disord Tech. 2007:20(1):33-5 https://doi.org/10.1097/01.bsd.0000211229.81930.80.

11. Tang JA, Scheer JK, Smith JS, et al. The impact of standing regional cervical sagittal alignment on outcomes in posterior cervical fusion surgery. Neurosurgery. 2015;76(Suppl 1):S14-21 https://doi.org/10.1227/01.neu. $0000462074.66077 .2 b$

12. Sielatycki JA, Armaghani S, Silverberg A, et al. Is more lordosis associated with improved outcomes in cervical laminectomy and fusion when baseline alignment is lordotic. Spine J. 2016;16(8):982-8 https://doi.org/10.1016/j. spinee.2016.04.009

13. Hyun SJ, Kim KJ, Jahng TA, et al. Relationship between T1 slope and cervical alignment following multilevel posterior cervical fusion surgery: impact of T1 slope minus cervical lordosis. Spine (Phila Pa 1976). 2016:41(7):E396-402 https://doi.org/10.1097/BRS.0000000000001264.

14. Celestre PC, Dimar JR 2nd, Glassman SD. Spinopelvic parameters: lumbar lordosis, pelvic incidence, pelvic tilt, and sacral slope: what does a spine surgeon need to know to plan a lumbar deformity correction. Neurosurg Clin N Am. 2018;29(3):323-9 https://doi.org/10.1016/j.nec.2018.03.003.

15. Obeid I, Boissière $\mathrm{L}$, Yilgor $\mathrm{C}$, et al. Global tilt: a single parameter incorporating spinal and pelvic sagittal parameters and least affected by patient positioning. Eur Spine J. 2016;25(11):3644-9 https://doi.org/10.1007/ s00586-016- 4649-3.

16. Furlan JC, Catharine CB. Psychometric analysis and critical appraisal of the original, revised, and modified versions of the Japanese Orthopaedic Association score in the assessment of patients with cervical spondylotic myelopathy. Neurosurg Focus. 2016:40(6):E6 https://doi.org/10.3171/2016.3. FOCUS1648.
17. Vernon H. The Neck Disability Index: state-of-the-art, 1991-2008. J Manipulative Physiol Ther. 2008;31(7):491-502 https://doi.org/10.1016/j.jmpt. 2008.08.006.

18. Liu S, Yang SD, Fan XW, et al. Analyses of effect factors associated with the postoperative dissatisfaction of patients undergoing open-door laminoplasty for cervical OPLL: a retrospective cohort study. J Orthop Surg Res. 2019;14(1):161 https://doi.org/10.1186/s13018-019-1208-8.

19. Fong $\mathrm{PL}$, Chevillotte $\mathrm{T}$, Leglise $\mathrm{A}$, et al. Which parameters are relevant in sagittal balance analysis of the cervical spine? A literature review. Eur Spine J. 2018;27(Suppl 1):S8-15 https://doi.org/10.1007/s00586-018-5462-y.

20. Kato M, Namikawa T, Matsumura A, et al. Effect of cervical sagittal balance on laminoplasty in patients with cervical myelopathy. Global Spine J. 2017 7(2):154-61 https://doi.org/10.1177/2192568217694011.

21. Jiang $Y Q$, Li $X L$, Zhou $X G$, et al. A prospective randomized trial comparing anterior cervical discectomy and fusion versus plate-only open-door laminoplasty for the treatment of spinal stenosis in degenerative diseases. Eur Spine J. 2017;26(4):1162-72 https://doi.org/10.1007/s00586-016-4878-5.

\section{Publisher's Note}

Springer Nature remains neutral with regard to jurisdictional claims in published maps and institutional affiliations.
Ready to submit your research? Choose BMC and benefit from:

- fast, convenient online submission

- thorough peer review by experienced researchers in your field

- rapid publication on acceptance

- support for research data, including large and complex data types

- gold Open Access which fosters wider collaboration and increased citations

- maximum visibility for your research: over $100 \mathrm{M}$ website views per year

At BMC, research is always in progress.

Learn more biomedcentral.com/submissions 